\title{
Combustion of Sewage Sludge and Coal Powder
}

\author{
F. Kirzhner, V. Sherbaum, G. Borodyanski, R. Armon, and B. Chudnovsky
}

\begin{abstract}
The technology to facilitate liquid sewage sludge disposal with minimum energy consumption for primary drying before incineration in a furnace is proposed. The possibility to use an industrial boiler was studied experimentally. The experimental test-rig was developed at Technion (Israel Institute of Technology) and the proposed concept was demonstrated successfully. Sewage sludge from municipal wastewater plants with a moisture content of up to 95-99\% combined with pulverized coal and liquid light fuel at various ratios was burnt. Sewage sludge co-combustion leads to an insignificant temperature reduction inside the furnace, and is able to provide stable combustion with low NOx and $\mathrm{CO}$ emissions.
\end{abstract}

Index Terms-Component, formatting, sewage sludge, liquid, incineration.

\section{INTRODUCTION}

The objective of the present study was to burn liquid sewage sludge disposal by furnace incineration without preliminary desiccation as this requires additional energy consumption [1], [2].

The annual USA and Europe market for sludge environmental services is over 16 million tons of sewage sludge (dry mass), according to world industry sources estimation [3]. This market is expected to grow in parallel with wastewater treatment and reuse increase. Recently, the amount of wastewater processed in sewage treatment plants (STP) has increased annually by 3\% [4]. Most of these plants include biological treatment. The disposal of sewage sludge from urban wastewater treatment plants became an important issue due to the prerequisite to minimize its environmental pollution impact. Since land-filling is not a suitable solution according to environmental point of view, a thermal treatment process proved to be the most appropriate solution. Combustion of sewage sludge mixed with coal, in a conventional incinerator system is an attractive alternative that provides partial compensation for sludge disposal cost and concurrent energy production.

Sludge combustion provides an amalgamation of several advantages which cannot be found in other alternative treatments. Among these advantages, a highly significant reduction in volume (to ash) and cost reduction of sludge process. The resulting dry ash accounts for $10 \%$ of the initial volume and it is free from toxic organic constituents that were burnt off [5]. Furthermore, the calorific value of the dry sludge corresponds to that of brown coal and it may be recovered through combustion [6].

Manuscript received March 5, 2014; revised May 10, 2014.

F. Kirzhner is with the Department of Civil and Environmental Eng., Technion, Israel Institute of Technology, Haifa, Israel (e-mail: kfelix@tx.technion.ac.il).
In the last few years, utilities have become interested in co-firing biofuels with coal and other fossil fuels, applying wood wastes and other solid forms of biomass to increase of capacity of power generating plants [7]-[11]. Initially, co-firing has been considered as a mean to reduce greenhouse gas emissions from fossil energy generation operations. Biomass co-firing with coal proved to be the most inexpensive method to generate green power in a utility plant [7], [12]-[17]. Also from the economic point of view prospect of the joint combustion of sludge and coal in power plants can be an attractive option since it allows the use of existing infrastructures, which are already equipped with the appropriate devices for flue gaseous emission control [18]. Furthermore, in near future new regulations will highly restrict the actual disposal procedure of municipal sewage sludge. Based on soil and groundwater protection, sterner requirements will have to be met in regard to pollution level of sewage sludge, limiting its use as fertilizer [19].

In the present study liquid sewage sludge was burnt in a furnace without preliminary desiccation and its joint combustion with light fuel and pulverized coal has been investigated under laboratory conditions. The novelty of the present research is the availability co-firing of liquid sludge with other fuels that has not yet been determined.

\section{METHODS}

The train for coal powder supply includes an air heater, where the compressed air is heated up to $70^{\circ} \mathrm{C}$, material conveying vacuum pump DF1-3 (Vaccon Co., Inc., USA) and a coal powder tank. Due to ejector internal low pressure, created by compressed air, a pump sucks the coal powder from a coal silo. Subsequently the coal powder/air mixture is delivered to burner. Operational quality of the test rig was tested by boiler efficiency measurements. Efficiency of the boiler was calculated according to the ASME PTC-4 indirect method. The measurements of combustion products' temperature at the exit which was more than $200^{\circ} \mathrm{C}$ and mass flow rates of coal, liquid fuel and air allowed calculating the boiler efficiency. It was equal to $89.8 \%$ (based on low heat value - LHV).

For smooth transfer from light fuel to pulverized coal operation, a possibility of gradual decrease of flow rate of light fuel was studied. For this experiment, the boiler operation automatic control has been switched off and a manual control of light fuel flow rate was performed. The results demonstrated steady burning and satisfactory quality of fuel spray. The constant burning observed at input pressure range of 2-10 bars for inlet fuel nozzle and a mass flow rate $1.5-3.4 \mathrm{~kg} / \mathrm{h}$. Calibration results are shown in Fig. 1.

Fig. 2 shows calculation results of sewage sludge pump 
pressure vs. nozzle diameter of working air for a given sewage sludge flow rate at $2 \mathrm{~g} / \mathrm{s}$. It can be seen that smaller nozzle diameter is required for increased pressure. It is important to note that air mass flow rate decreased higher with pressure rise. For example, when cross section area of air nozzle decreases by a factor of 3 , required pressure increased 2.5 times. The explanation is that while air velocity increases with pressure it enhances the suck effect of the pump and less air flow rate is required to achieve the same sewage sludge mass flow rate.

Preliminary measurements of sewage sludge solid fraction showed that dry mass is about $1 \%$. Due to this low mass concentration, it was decided to use an industrial color sprayer for sludge supply. Experiments with this device showed that it enables to provide good quality of sewage sludge spray.

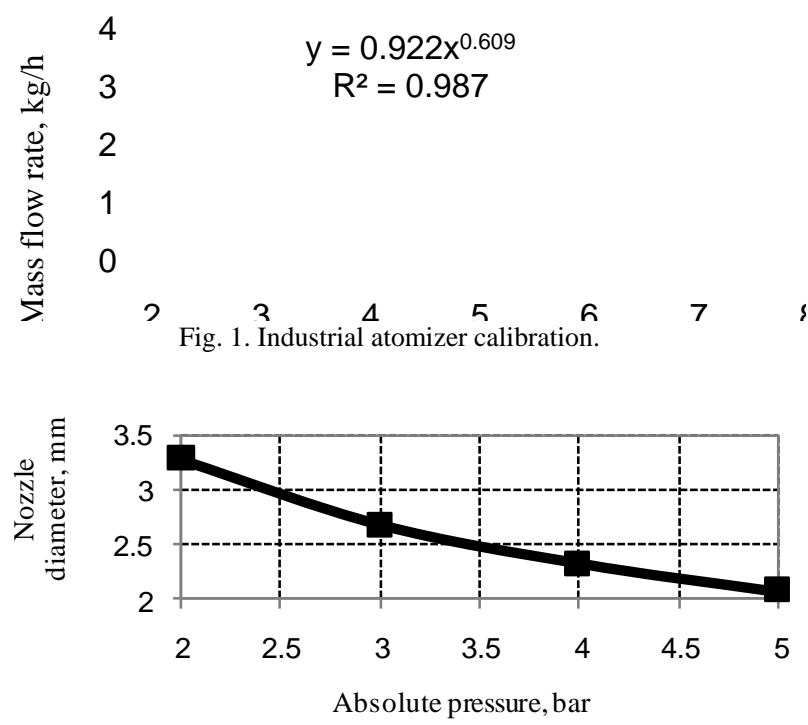

Fig. 2. Nozzle diameter of working air and pressure effect on sewage sludge transport pump.

\section{A. Open Test Rig}

In order to follow up closely the burning process the system was mounted on a special "OPEN" test-rig (Fig. 3). The open test-rig was designed and manufactured for direct visual observation and measurements during "cold" and "hot" tests. The test rig has transparent parts and all stages of burning such as ignition, formation of liquid spray, and coal distribution can be directly observed. Fig. 3a shows a general view of the experimental test-rig. Burning process with minimum mass flow rate of liquid fuel which provides stable combustion is shown in Fig. $3 b$.

The combined burner provides light (liquid) fuel and coal powder supply. The light fuel is carried to a swirl atomizer which is installed into the burner axis. The motive of liquid fuel (oil) supply aimed at is burning support: due to high heat losses under our specific operation conditions certain amount of liquid fuel should be kept available. In full scale boiler operation, this problem does not exist since relative heat losses inside the furnace are significantly lower. Coal powder and primary air mixture are delivered through the 10 nozzles with a $5 \mathrm{~mm}$ diameter located inside the burner case. The secondary air portion for coal burning is fed through the annular swirler and forming recirculation zone which provides stable burning.

The standard system of the burner Cuenod NC6 for the light fuel supply was used. The standard control system has been modified and control and variation of the light fuel flow rate was provided by bypass pressure control valve.

The tests with open test rig allowed receiving the following results:

1) Minimum mass flow rate of the light fuel for the stable burning was $0.12-0.15 \mathrm{~g} / \mathrm{s}$ and an atomizer pressure drop equal to $0.2-0.3$ bars, but spray quality for this case was very poor (light fuel flows as liquid jet without droplets formation). Air mass flow rate was $8 \mathrm{~g} / \mathrm{s}$. A spray cone was formed for a pressure difference more than 3 bars (fuel mass flow rate was $0.54 \mathrm{~g} / \mathrm{s}$ ).

2) Air heating up to $200-250{ }^{\circ} \mathrm{C}$ improves burning stability. Minimum pressure drop at the atomizer of the light fuel was equal to 0.5 bars.

3) Combined burning of the light fuel-coal was demonstrated.

4) Coal did not burn without light fuel support. A stable burning was observed for a coal mass flow rate of $0.8-1.3 \mathrm{~g} / \mathrm{s}$, requiring an air pressure of vacuum pump equal to $2.2-2.4$ bars.

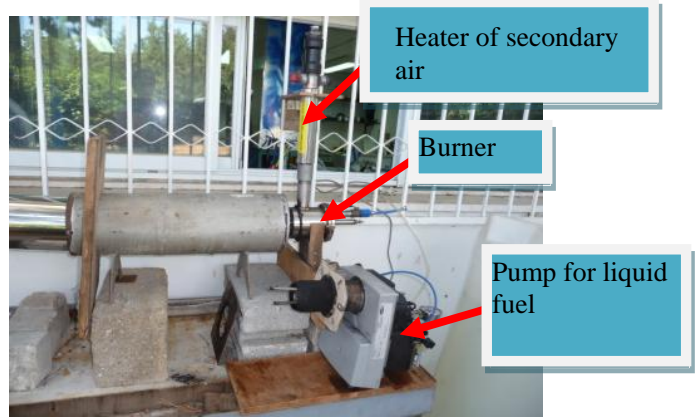

(a)

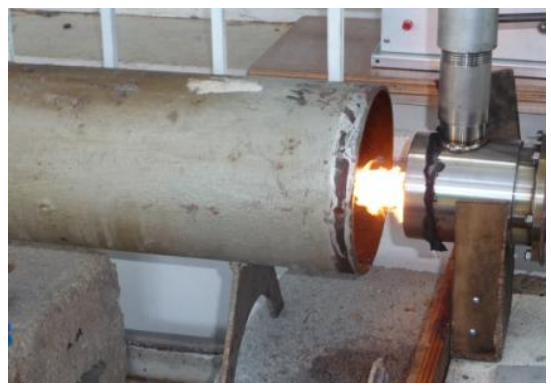

(b)

Fig. 3. "Open" test-rig: (a) general view; (b) experiment with minimum mass flow rate of liquid fuel which provides stable combustion.

\section{B. Laboratory Test Rig (LTR)}

Following the open test-rig, a Laboratory Test Rig for coal and sewage sludge combustion was designed, constructed and demonstrated by Technion. Main components of the Laboratory Test Rig and main devices for combined fuel supply are shown in Fig. 4b.

Boiler Logano G215 was used in the LTR complex. Primarily the boiler was tested with light fuel solely. A stable boiler operation was obtained. The fuel mass flow rate was in the range of $3.7-4.1 \mathrm{~kg} / \mathrm{h}$ that was in a good agreement with manufacturer's data. Material conveying vacuum pump DF1-3 was used for pulverized coal supply. 


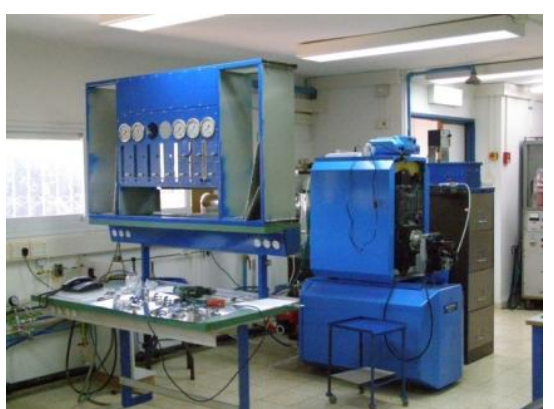

(a)

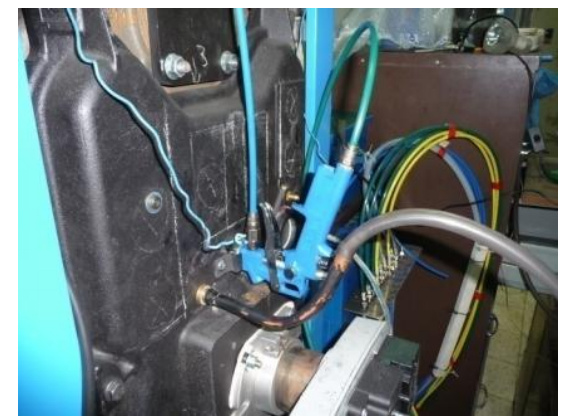

(b)

Fig. 4. Laboratory test-rig. (a) General design (left: control and measure board, right: boiler); (b) Devices for combined fuel supply (from left: sewage sludge feeder, air supply and pulverized coal).

The order of switching from liquid fuel to pulverized coal was carried out, as follows:

1) Short time boiler operating with liquid fuel (boiler heating);

2) Short time pulverized coal delivered together with liquid fuel;

3) Liquid fuel flow rate decreases and boiler operates with pulverized coal with minimum support of liquid fuel.

The LTR includes the following systems:

a) Boiler;

b) Combined burner (liquid fuel/coal);

c) Pipeline for liquid fuel supply;

d) Pipeline for coal powder supply (line 1);

e) Pipeline for sewage sludge supply (line 2);

Two electric heaters at 6.5 and $0.45 \mathrm{~kW}$ provides an air heat up of $300^{\circ} \mathrm{C}$ for the burner's swirler and $70{ }^{\circ} \mathrm{C}$ for pulverized coal delivery. Air at $300{ }^{\circ} \mathrm{C}$ is divided into two flows according to the LTR operation requirements. One pipeline provides coal powder and the second one - sewage sludge. To deliver coal powder and sewage sludge to the boiler, two ejecting devices were mounted. Air is heated for improvement of ignition and burning conditions of coal powder.

\section{Test Methodology}

The aim of the tests was to burn coal-light fuel mixture with total heat power approximately of $40 \mathrm{~kW}$ as standard. Mass flow rate of the sludge solution should be close to the total mass of fuel flow rate. Relationship between light fuel and coal is approximately 30:70 \% to support combustion. Rendering this conditions, it was found that light fuel mass flow rate should be equal to $0.3-0.4 \mathrm{~g} / \mathrm{s}$ and a coal mass flow rate of about 1.1-1.2 g/s. Sewage sludge mass flow rate was 1.2-1.5 g/s. Under these conditions, the boiler heat power and air parameters were calculated.

Values of the heat power, $P$ is:

$$
P=0.3 \cdot 10^{-3} \cdot 42350+1.1 \cdot 10^{-3} \cdot 25270=40.5 \mathrm{~kW}
$$

For maximum light fuel and coal mass flow rates:

$$
P_{\max }=0.4 \cdot 10^{-3} \cdot 42350+1.2 \cdot 10^{-3} \cdot 25270=47.3 \mathrm{~kW}
$$

Required air mass flow rate for the given coefficient of excess air ( $\alpha) \alpha=1.2$ is:

$$
m_{\text {air }}=\alpha\left(m_{l . f} \cdot 14.7 \cdot 42350+m_{c} \cdot 9.43\right)
$$

For obtained nominal values of both fuels:

$$
m_{\text {air }}=1.2 \cdot(0.3 \cdot 14.7 \cdot+1.1 \cdot 9.43)=17.8 \mathrm{~g} / \mathrm{s}
$$

Measurements of the air mass flow rates of fuel and sludge transport resulted as follows: Coal transport air $-1 \mathrm{~g} / \mathrm{s}$, ejected air $-1 \mathrm{~g} / \mathrm{s}$ (required for enhancement of velocity in the transport pipe), sewage sludge sprayer $-1 \mathrm{~g} / \mathrm{s}$.

Thus, mass flow rate of the main air is $17.8-3=14.8 \mathrm{~g} / \mathrm{s}$.

Start-up of the LTR operation:

1) Set mass flow rate of the main air equal to $7-8 \mathrm{~g} / \mathrm{s}$.

2) Set light fuel pressure equal to 10 bars.

3) Ignite light fuel by gas igniter. After ignition to increase air mass flow rate till $18 \mathrm{~g} / \mathrm{s}$ and switch on a heater of main air. Maximum temperature of the furnace volume should be equal to approximately $1000^{\circ} \mathrm{C}$.

4) Heat the furnace volume so that to achieve water temperature was approximately $55-60^{\circ} \mathrm{C}$. This temperature is fixed by a logometric thermocouple.

5) Increase main air mass flow rate till $29 \mathrm{~g} / \mathrm{s}$.

6) Deliver the coal powder into the furnace volume and to reduce light fuel pressure till 4 bars. Switch on a stop-watch together with the coal powder supply.

7) Open bypass line and to reduce the main air mass flow rate till $19 \mathrm{~g} / \mathrm{s}$.

8) Reduce mass flow rate of light fuel till $0.3 \mathrm{~g} / \mathrm{s}$; this corresponds to inlet pressure 1.4 bars.

The LTR was equipped by 7 thermocouples type K located at the several points of boiler. Inlet air mass flow rates was measured by rotameters, light fuel mass flow rate fuel defined according to pressure gauge reading and recalculated through the calibration chart, Fig. 1. Mass flow rate of coal is found as weight difference of coal tank before and after test and test duration, which measured by stop-watch. Equivalence ratio was calculated according to oxygen content of the burning products. This value is checked by input mass flow rates of fuel and air.

Content of burning product was measured by gas analyzer Biosystem PHD6. NOx, CO- gases content measurements (corrected to $3 \%$ of $\mathrm{O}_{2}$ ) for light fuel, (corrected to $6 \%$ of $\mathrm{O}_{2}$ ) for coal with supported light fuel and sewage sludge burning processes

\section{RESULTS AND DISCUSSION}

The distribution of flame temperatures in the combustion chamber is shown in Fig. 5. The distribution of flame 
temperature through flame length is shown in Fig. 6. It was found the optimal point for sewage sludge with additional air delivery, located at a distance of 2.5 diameters from the coal burner. As can be seen from the experimental data, sewage combustion almost does not impact temperature and flame stability, including conditions where combustion in the furnace high heat losses to the furnace wall occurs. Maximum temperature was achieved for excess air ratio of 1.1-1.2.

Results of simultaneous burning of combined fuel (light fuel oil (LFO) + coal + sewage sludge) showed that effect of sludge feed on burning temperature is very close to values which were received during light fuel experiments. The maximum coal fraction in combined light fuel/coal was equal to $63 \%$. The possible causes of this outcome are the enhanced high heat removal by water jacket, low temperature nearby coal exit of the burner and relatively low temperature of transport air for coal (difficulties with pressure control and air suction).

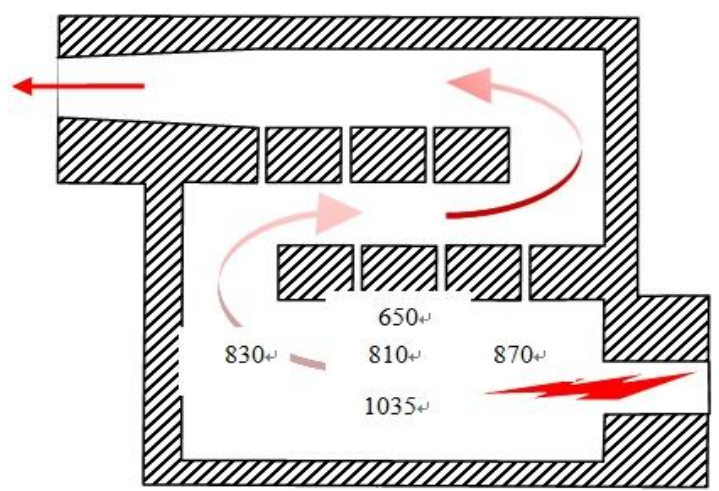

Fig. 5. Temperature in the combustion chamber. Coal with supported LFO and sewage sludge.

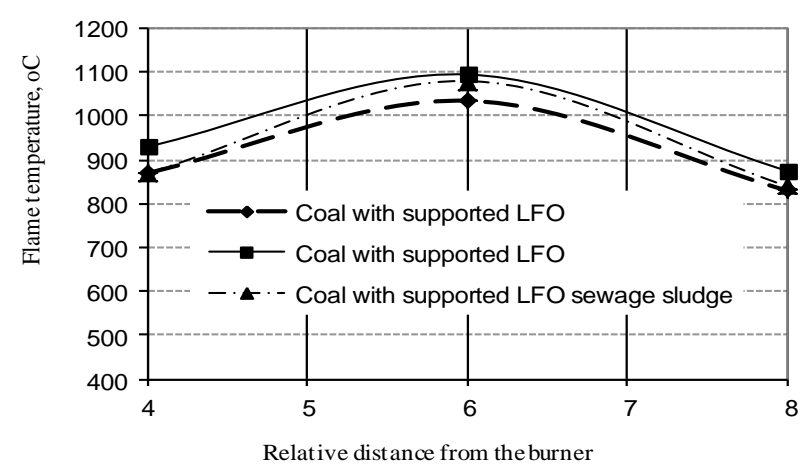

Fig. 6. Flame temperature distribution through flame span.

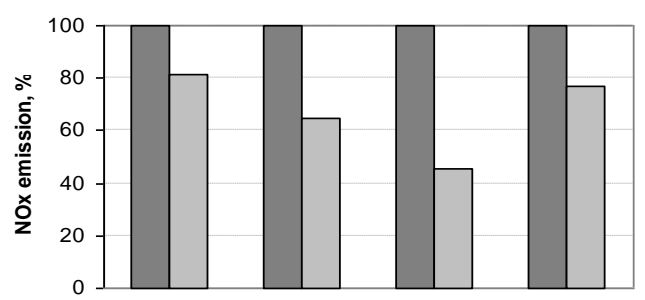

$\square$ Coal with supported LFO $\square$ Coal with supported LFO and sludge Fig. 7. Results of the NOx measurements.

The NOx measurements for combustion of coal with supported light fuel and sewage sludge are shown in Fig. 7. As can be seen, the addition of sewage sludge reduces NOx emission at $19-55 \%$. The reason for the observed phenomenon is the firing system design that provides staging combustion for sludge and light fuel/coal firing process. Also addition of water which is present in the sewage sludge leads to NOx reduction. Therefore the developed concept allows to burn coal and sewage sludge mixture and at the same time to reduce NOx formation.

Comparison of $\mathrm{CO}$ emission results shows that $\mathrm{CO}$ value reached a value of $250 \mathrm{mg} / \mathrm{m}^{3}$. The cause of CO increase in comparison with typical furnaces is that dimensions of the tested furnace corresponds to light fuel firing and does not fit coal firing. Moreover, due to the high heat losses in the furnace, the flame temperature is low as opposed to typical coal firing units (up to $1400-1500{ }^{\circ} \mathrm{C}$ ). This shows that is possible to burn light fuel and sewage sludge as emulsion even in a typical boiler. Regarding NOx and CO emissions removal, our results are in agreement with dry water sludge burning experiments, performed in Germany [19].

\section{CONCLUSION}

Sewage sludge with additional air was delivered by an industrial sprayer to a point located at a distance of 2.5 diameters from the coal burner. This permutation provides a stable combustion of the coal at the initial flame zone without impacting sewage sludge when coal is burned out. At the same time, a fraction of the secondary air was fed with sewage sludge and it is able to provide staging combustion. As a result, NOx emissions decreased by $20-55 \%$, depending on coal fraction. $\mathrm{CO}$ emissions during light fuel oil firing were negligible. Coal burning leads to increase of $\mathrm{CO}$ content. The major reason for this phenomenon is that the boiler used in LTR is designed for LFO firing; therefore furnace dimension is not enough to provide a full combustion of the coal.

The performed tests showed that the general concept of the developed firing system for simultaneous burning of coal and sewage sludge is feasible. Stable burning was provided at a range of mass fuel/sludge ratio of $0.5: 1$. Sewage sludge co-firing leads to an insignificantly temperature reduction inside the furnace and is able to provide a stable combustion with a low emission.

\section{ACKNOWLEDGMENT}

This research was supported by the Israel Electric Corp. and the Center for Absorption in Science, Ministry of Immigrant Absorption, State of Israel. The contributions of V. Neiman in tests performing, and Dr. Yu. Nekhamkin in results discussions are hereby acknowledged.

\section{REFERENCES}

[1] Y. Zimmels, F. Kirzhner, and G. Borodyanski, "Apparatus and method of burning sewage sludge and generating power thereof," USA Patent, WO2007138592 (A2).

[2] G. Borodyanski, F. Kirzhner, and Y. Zimmels, "Methods and system for treating sewage sludge," USA Patent, Filled WO 2011024177 (A1).

[3] H. Tarchevski, "Standards for using sewage sludge in Israel and in the world," Water and Irrigation, vol. 475, pp. 14-19, 2006.

[4] J. Nadziakiewicz and M. Kozio, "Co-combustion of sludge with coal," Applied Energy, vol. 75, no. 3-4, pp. 239-248, 2003.

[5] P. A. Vesilind and T. B. Ramsey, "Effect of drying temperature on fuel value of wastewater sludge," Wastewater Management and Research, vol. 14, pp. 189-196, 1992. 
[6] R. Römer, "Thermal treatment of sewage sludge-combustion, drying energy recovery, emissions," Klärschlamm Entssorgung 1, Daten-Dioxine, Entwässerung, Verwetung, VDI GbmH, pp. 250-271, 1991.

[7] J. M. Ekmann, J. C. Winslow, S. M. Smouse, and M. Ramezan, "International survey of co-firing coal with biomass and other wastes," Fuel Processing Technology, vol. 54, pp. 71-88, 1998.

[8] N. S. Harding and B. R. Adams, "Biomass as a reburning fuel -a specialized co-firing application," Biomass Bioenergy, vol. 19, pp. 29-45, 2000.

[9] A. B. Ross, J. M. Jones, S. Chaiklangmuang, M. Pourkashanian, A. Williams, K. Kubica, and J. T. Andersson et al., "Measurement and prediction of the emission pollutants from the combustion of coal and biomass in a fixed bed furnace," Fuel, vol. 81, pp. 571-582, 2002.

[10] M. Sami, K. Annamalai, and M. Wooldridge, "Co-firing of coal and biomass fuel blends," Progress in Energy and Combustion Science, vol. 27, pp. 171-214, 2001.

[11] G. Skodras, P. Grammelis, P. Samaras, P. Vourliotis, E. Kakaras, and G. P. Sakellaropoulos, "Emission monitoring during coal waste wood co combustion in an industrial steam boiler," Fuel, vol. 81, pp. 547-554, 2002.

[12] J. J. Battista, E. Hughes, and D. A. Tillman, "Biomass co-firing at seward station,” Biomass Bioenergy, vol. 19, pp. 419-447, 2000.

[13] C. Dong, B. Jin, Z. Zhaong, and J. Lan, "Tests on co-firing of coal and MSW in a circulating fluidized bed," Energy Conversion and Management, vol. 43, pp. 189-199, 2002
[14] E. Hughes and D. A. Tillman, "Biomass co-firing: status and prospects,” Fuel Processing Technology, vol. 54, pp. 27-42, 1996.

[15] P. J. Hus and D. A. Tillman, "Co-firing multiple opportunity fuels with coal at Baily generating station," Biomass Bioenergy, vol. 19, pp. 385-394, 2000.

[16] B. Leckner, "Emissions from fluidized bed combustion of biomass," presented at IEA Workshop on FBC of Unconventional Fuels, 1999.

[17] D. A. Tillman, "Cofiring benefits for coal and biomass," Biomass Bioenergy, vol. 19, no. 6, pp. 363-364, 2000.

[18] D. O. Reimann, "Process for sewage sludge disposal," Umwelt Bd., vol. 25, no. 5-6, pp. 238-241, 1995.

[19] B. Roper and F. J. Kipshagen, "Operation experience with sewage sludge and waste wood co-combustion in the Berrenrath power plant," VGB PowerTech, vol. 8, pp. 60-64, 2003.

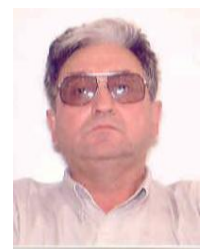

Felix Kirzhner is a senior level researcher who has experience in processing technologies and in environmental aspects of waste utilization.

Dr. Kirzhner got the D.Sc. degree in mining engineering, mining institute, Moscow in 1985. Since 1991, he was fully employed as a researcher at the Faculty of Civil and Environmental Engineering, Technion, the Israel Institute of Technology. His is the author of about 50 international scientific publications. 